\title{
CONSUMER'S EXPERIENCE OF TEA PACKAGING AS ENVIRONMENT-FRIENDLY
}

\author{
Jesenka Pibernik (D), Tamara Tomašegović (D), Sanja Mahović Poljaček (D), Anđela Madžar \\ University of Zagreb, Faculty of Graphic Arts, Zagreb, Croatia
}

\begin{abstract}
The packaging design is perceived as environmentally friendly when deploying established "green" conventions for design, materials, form, colours, and symbolism. The paper aims to determine which tea packaging design choices mainly influence consumer's impression of eco-friendliness. After the sustainable solutions for packaging form were examined, additional attributes of sustainability in terms of the materials were established. These were the shape of the packaging for the ease of use, closing solution, content visibility, printing paper perception, and other use-friendly attributes. Upon experimenting with six versions of prototype designs, following the guidelines of user-centered design, the final prototype has been selected for further development and testing. The alternatives for appropriate printing ink, printing pressure, and substrate were tested on various paper samples. Due to the various recycled substrate's surface colours and morphology, the flexographic printing process resulted in various shades of image colours and line sharpnesses. To determine correlations between different attributes and make a final design decision, the subjective quality assessments were implemented.
\end{abstract}

Keywords: Tea Packaging, User-centered Design, Eco-friendly, Recycling, Evaluation

\section{INTRODUCTION}

Packaging waste is a dominant contributor in today's world and responsible for half of the waste in the globe (Hannah and Roser, 2020). Due to the problems the waste creates for the environments, consumers are increasingly associating sustainability with higher quality and awareness. One group of consumers that are significantly concerned about environmental pollution and packaging attributes are organic tea consumers. Due to its graining substance, the tea can be packaged in a variety of ways having in mind that the design and materials of the package contribute significantly to the perception of sustainability. Filter bags are often applied to differentiate the portions. The tea filter bags are packaged in paper, a combination of paper and plastic, or a combination of paper, plastic, and aluminum, so-called multilayer packaging. Besides, each filter bag generally has a thread sewn onto the bag or joined with a small metal. At the end of the thread, there is a paper with a print that is often coated. The coating, as well as the paint, make it difficult to decompose, which makes the product less eco- friendly. Therefore, bulk tea packaging is considered a eco-friendlier solution.

Aluminum and tinplate, combined or laminated, is often used for the bulk tea packaging. The metal is soft enough to be easily cut and bent into air-tight containers, which extend the shelf life of the product. The problem with metal packaging is that it does not convey eco-efficienct (Better Meets Reality, 2020). For its price, lightweight and flexibility, cardboard is often used for the smaller amounts of bulk tea packaging. Using recycled paper as raw material for packaging has multiple environmental benefits and economic savings. The cardboard needs to have an additional inner layer for different purposes: aesthetics, prevention of damage and heat, or preservation of freshness. Cardboard packaging can protect the tea against the light in two ways. One way is using a larger amount of paper-based material which will make the layer thicker and denser. The advantage of this is the ease of recycling, and the disadvantage is the use of a larger amount of material. Another way is to use a minimum amount of paper. Such a material can be transparent, which is why it needs a coating or a layer of dark paint on the outer surface which prevents the penetration of light. The downside of this alternative is that the paint and coating need to be removed before recycling.

From an environmental point of view, the most acceptable packaging is a combined packaging made of recycled cardboard and transparent foil. The tea is protected from moisture and heat by a foil that acts as an insulator. Currently, transparent foil and PLA coating are the most common. PLA stands for polylactic acid and is a resin made from corn starch which is not bio-degradible (BioSphere Plastic, 2020). It is degradable only in industrially produced conditions. Temperature must be $70^{\circ} \mathrm{C}$ or higher and humidity must be $70 \% \mathrm{RH}$ at least. So PLA is not an option for eco-friendly solution. The transparent foil is usually separated from the material that protects the tea from light and joined only at the ends of the packaging while the middle is free. Such packaging can be completely recycled if the foil is sorted into containers 
intended for that purpose. The economy of space is important, as well as safety concerns. The package must preserve and protect the tea from moisture and exposure to oxygen, it must be practical, but it also needs an artistic presentation to attract gourmet shoppers. Packaging must balance substance and style with the sense that buying the product makes consumers feel they belong to a special group (Better Meets Reality, 2020). Minimalism is an effective aesthetic for designing sustainable packaging.

To determine which tea packaging design choices mainly influence consumer's impression of ecofriendliness we have conducted the three steps experiment. The tea packaging final design decision was based on the results of several iterations of prototype testing, the consumer's interview, and the questionnaire.

\section{METHODS}

\subsection{User-centered design process}

The user-centered design process for packaging resulted in six successive prototypes. Each prototype was tested and subsequently improved. The process began with the interview of a group of six eco-friendly tea consumers. Their experiences with tea packaging provided the designer with valuable insights. Some of the opinions the consumers shared were:

- The common tea packaging container is high and narrow, which makes it impractical.

- The additional elements for closing often crack.

- $\quad$ The consumers prefer the content to be visible from the outside.

Based on the input, the packaging designer created the first solution for the final container in the shape of a five-sided prism with a closing solution without the use of additional materials (Figure 1). The shape of the prism made the packaging more resistant to material defects and overturning, and strong enough so that thinner paper is required. The closed packaging additionally retained the tea freshness because it was shrunk at the top. The corresponding dieline template layout was appropriately created to use the maximum space of the printing format (Figure 2).

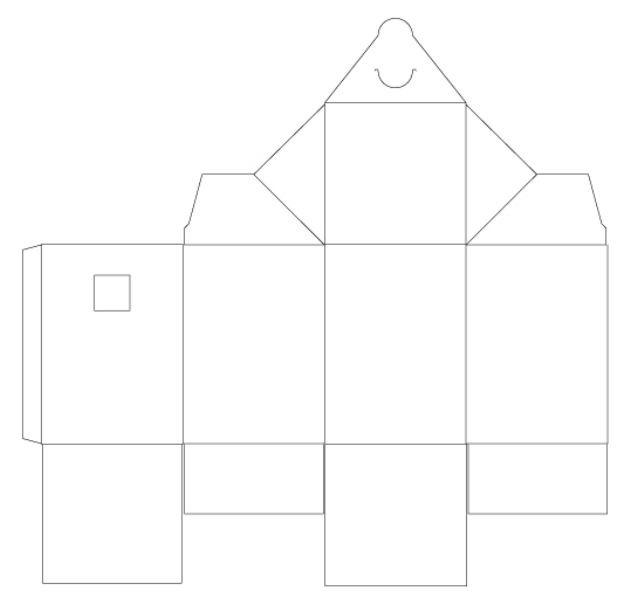

Figure 1: The first testing prototype

For the second solution, the distance of the "closing" valve was prolonged. The lateral sides were beveled for greater convenience (Figure 3). For the third solution, the opening was reduced and a different approach for closing was made (Figure 4). Connected flaps that overlap during closing were impractical because they created resistance to closing by accumulating materials that are interconnected. The bottom of the fourth design was reconfigured since it turned out to be a weak point during the testing (Figure 5). The fifth solution was designed with lateral sides to compresses the opening, which significantly reduced the possibility of the accidental fall out of content. When opened, the packaging expanded, making it more convenient to use. The width of the opening depended on the thickness of the paper because in case of bends and stretches the cracking could occur. The closing flap was problematic 
as corners were found to break very quickly (after only a few openings and closures) (Figure 6). Therefore, in the final design (sixth prototype), the first solution of the closing valve was re-applied. The bottom sides overlapped, which secured the contents, especially because only the inner side will be glued with cellophane, while the other sides will be glued paper to paper (Figure 7). The end on the closing cutout was reduced from half a circle to $3 / 4$ of its size (Figure 8 ).

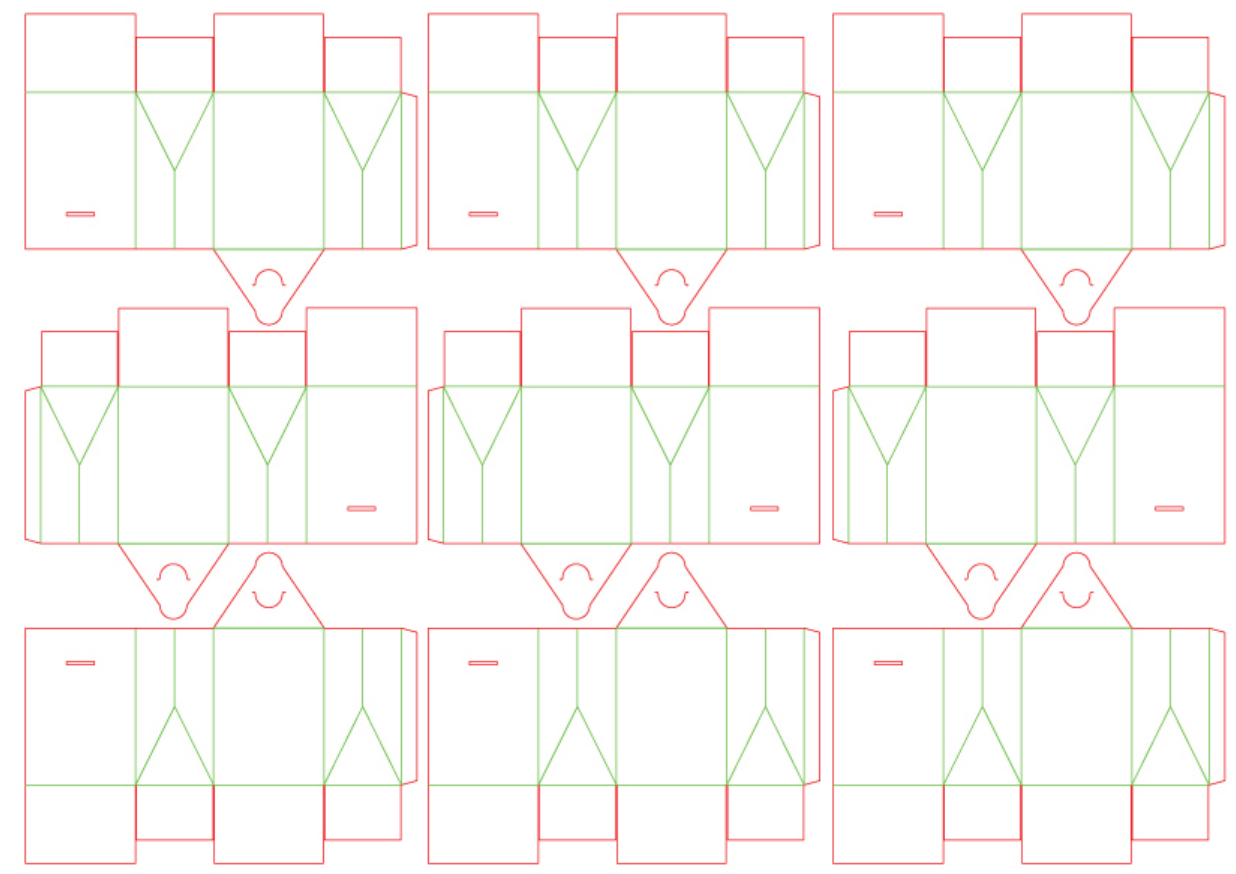

Figure 2: The third testing prototype

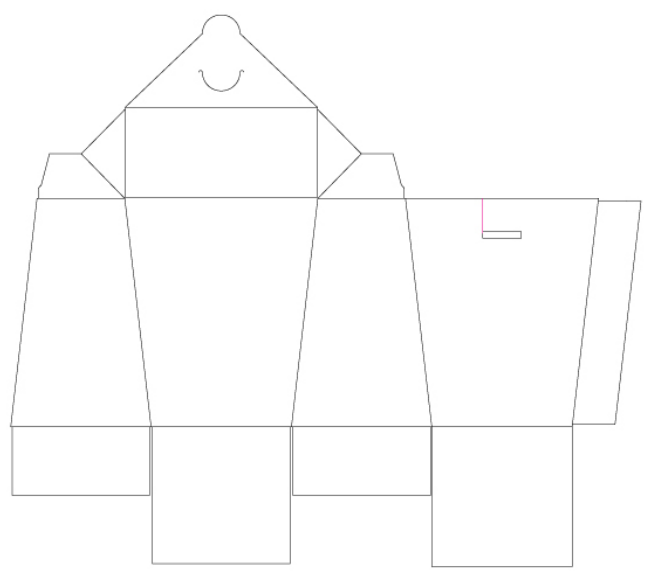

Figure 3: The second testing prototype 


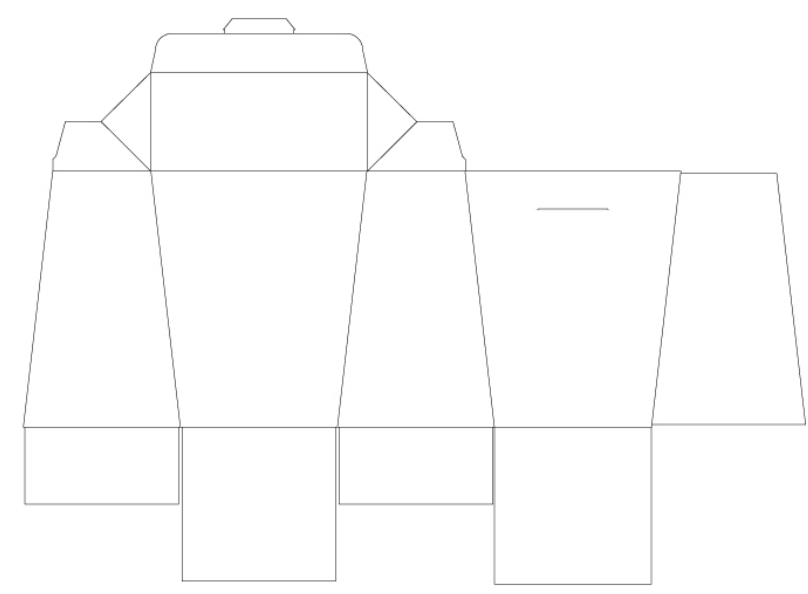

Figure 4: The third testing prototype

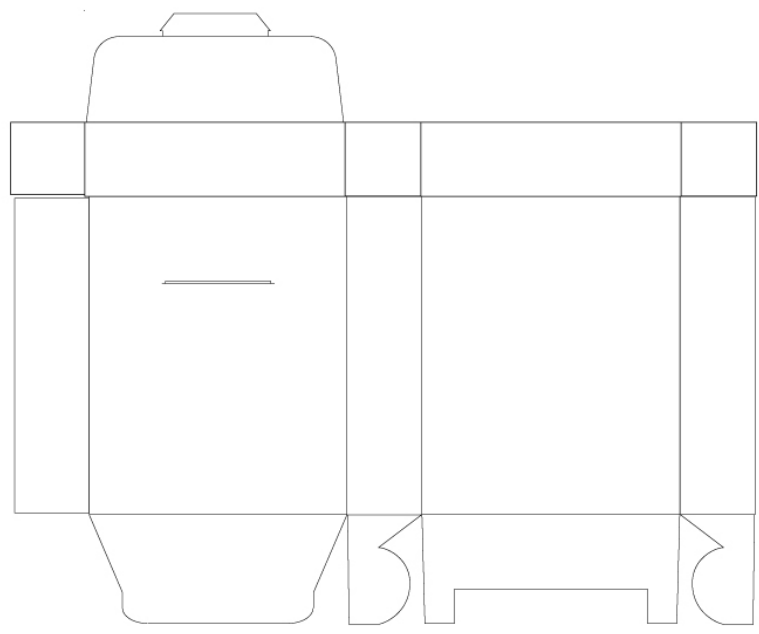

Figure 5: The fourth testing prototype

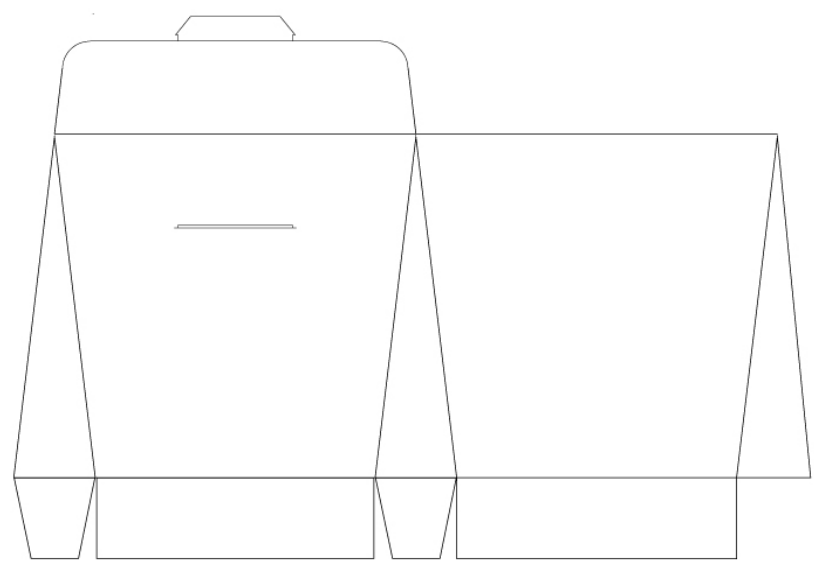

Figure 6: The fifth testing prototype 


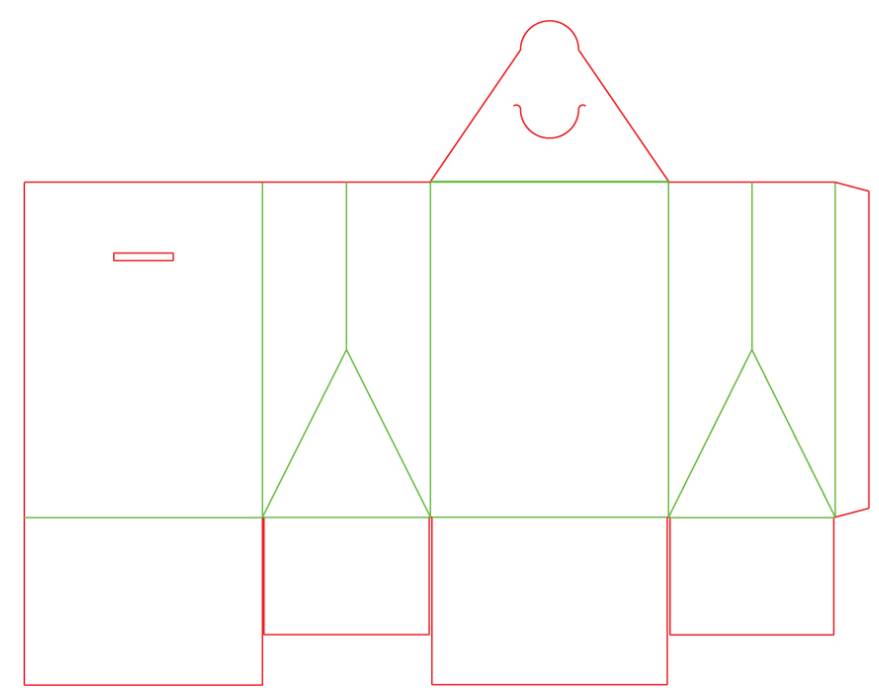

Figure 7: The sixth, final testing prototype

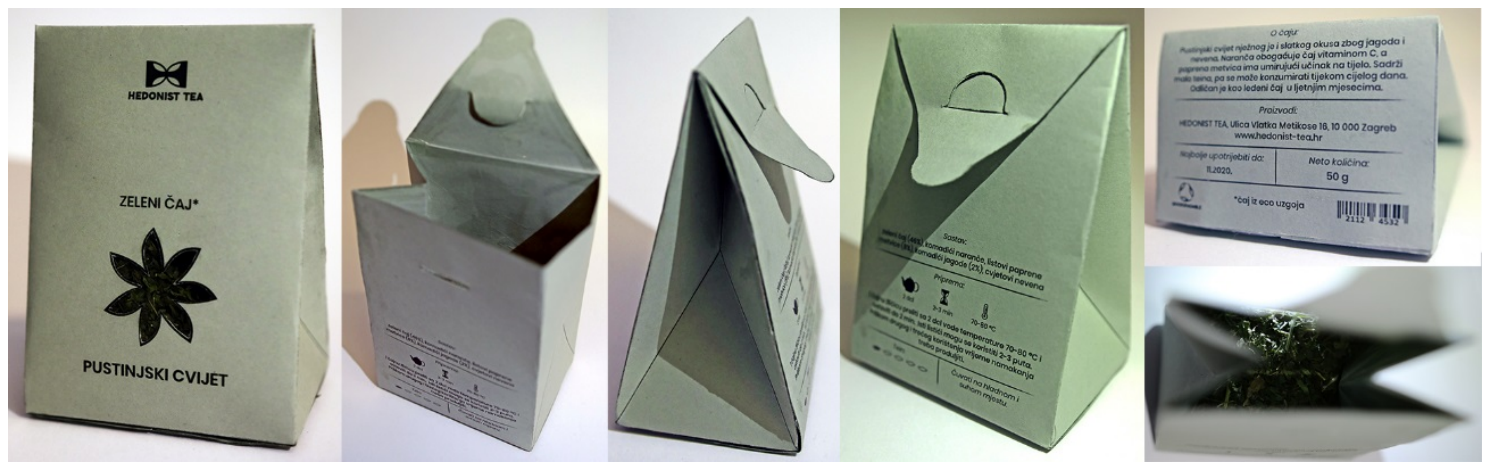

Figure 8: The final packaging design

\subsection{The binder, substrate, ink, and printing process selection}

Modern ecological binders show equal or better mechanical properties than non-ecological ones (Gasket,2020). Some of the options considered were solvent-free water-based adhesives with a low content of volatile organic compounds, solvent-free adhesives with a low content of volatile organic compounds or dextrin, and other natural starch-based adhesives. Each group had several types of adhesives to choose from. Water-based binders may be based on homopolymers, copolymers, polyvinyl alcohol, cohesive latex, etc. (Bond Tech Industries,2020).

The best choice is binders that can be composted. The product that can be composted must have the "OK compost" logo. This logo complies with the requirements of the EU Packaging Directive (94/62 / EEC). The certificate is obtained according to the European standard: EN 13432: 2000 for the packaging of composted material. In addition to the binders, this also applies to dyes and all other additives in the packaging industry.

After selecting the composting binder, an adequate dye should be selected. This choice is connected to the printing process and substrate selection. For this research, five recycled papers were selected (CordenonS, 2020; Cosper, 2020; Forest Stewardship Council, 2020; Mohawk, 2020; Felix Schoeller Group, 2020). Testing prototypes were made of paper $80 \mathrm{~g} / \mathrm{m} 2,100 \mathrm{~g} / \mathrm{m} 2,130 \mathrm{~g} / \mathrm{m} 2,140 \mathrm{~g} / \mathrm{m} 2,220$ $\mathrm{g} / \mathrm{m} 2$ and $300 \mathrm{~g} / \mathrm{m} 2$. After functional testing, we concluded that $80 \mathrm{~g} / \mathrm{m}^{2}$ was too thin and cracked after several uses, $300 \mathrm{~g} / \mathrm{m}^{2}$ was too stiff and thick to use, and the paper of the remaining weights was taken for further testing.

Data on papers can be seen in Table 1. Each paper has a Forest Stewardship Council certificate that "promotes the environmentally friendly, socially beneficial and economically sustainable management of the world's forests" (Forest Stewardship Council, 2020). All papers were recycled and uncoated. 
Flora papers are made of $30 \%$ of pulp that has been subjected to deinking flotation twice, $60 \%$ of primary woodless pulp, and $10 \%$ of cotton fibers (Cordenons, 2020). Since all papers were uncoated, the surface was rough, which is why etching and flexographic printing were considered. For the printing process to be truly environmentally friendly, attention should be paid to the way the printing plate is made, as well as to the compatibility of the printing plate with the used printing substrate (Sherin, 2008). Due to the elasticity of the printing plate, flexographic printing which offers the possibility of laser engraving of the printing plate was chosen. The plate is directly engraved with a laser, without the development process or use of aggressive solvents and harmful wastewater. The printing plate was made by the manufacturer Birkan $\mathrm{GmbH}$. It is made of EPDM material. EPDM is an elastomer - polymer synthetically obtained from ethylene, propylene, and a small proportion of one diene, and it is characterized by exceptional resistance. It is resistant to aging, the influence of the atmosphere, high and low temperatures, and electrical penetration, which means that the plate can be used for a long time.

Table 1: The papers characteristics and sample tagging

\begin{tabular}{|l|l|l|l|l|l|}
\hline PAPER/PRESSURE & A & B & C & D & E \\
\hline BRAND & MOHAWK & FLORA & FLORA & SCHOELLERS & SCHOELLERS \\
\hline COLOR & white & avorio & gigilio & light brown & dark brown \\
\hline WEIGHT & $220 \mathrm{~g} / \mathrm{m}^{2}$ & $130 \mathrm{~g} / \mathrm{m}^{2}$ & $100 \mathrm{~g} / \mathrm{m}^{2}$ & $140 \mathrm{~g} / \mathrm{m}^{2}$ & $140 \mathrm{~g} / \mathrm{m}^{2}$ \\
\hline $50 \mathrm{~N}$ & A1 & B1 & C1 & D1 & E1 \\
\hline $150 \mathrm{~N}$ & A2 & B2 & C2 & D2 & E2 \\
\hline $400 \mathrm{~N}$ & A3 & B3 & C3 & D3 & E3 \\
\hline
\end{tabular}

Printing took place at the Faculty of Graphic Arts in the laboratory for printing forms on the device: IGT Printability Tester F1. The samples measuring $5 \times 70 \mathrm{~cm}$ were cut from each paper. The pressure of the anilox roller on the printing plate was a constant of $300 \mathrm{~N}$. Each of the five papers was imprinted with three different pressures $(50 \mathrm{~N}, 150 \mathrm{~N}$, and $400 \mathrm{~N}$ ) to obtain 15 different imprint samples (Table 1). The most eco-friendly ink would be water-based, but due to the limitations of laboratory conditions, UV ink was used. The advantage of UV inks is fast drying without creating VOC (volatile organic) compounds. UV inks are in liquid form and need to be UV-cured before further use. They were dried in a UV dryer by Aktiprint $L$ with a radiation spectrum of UV lamps with a radiation intensity of $60 \%$. The drying speed was $4 \mathrm{~m} / \mathrm{s}$, with two passes during drying. The UV ink used for printing is PANTONE $363 \mathrm{U}$. The LAB value for this ink is: $L=50.19 ; a=-24.88$ and $b=24.05$. $L A B$ values of each sample are displayed in the HEX colour (Figure 9). The shades indicate that Group A imprints have the most similar values to PANTONE $363 \mathrm{U}$ colour. A1, B1, and C1 sample $L$ value is increased, which means that the colours are brighter. D1 and E1 have the lowest value of a, which means that these imprints colours contain the least green pigment.

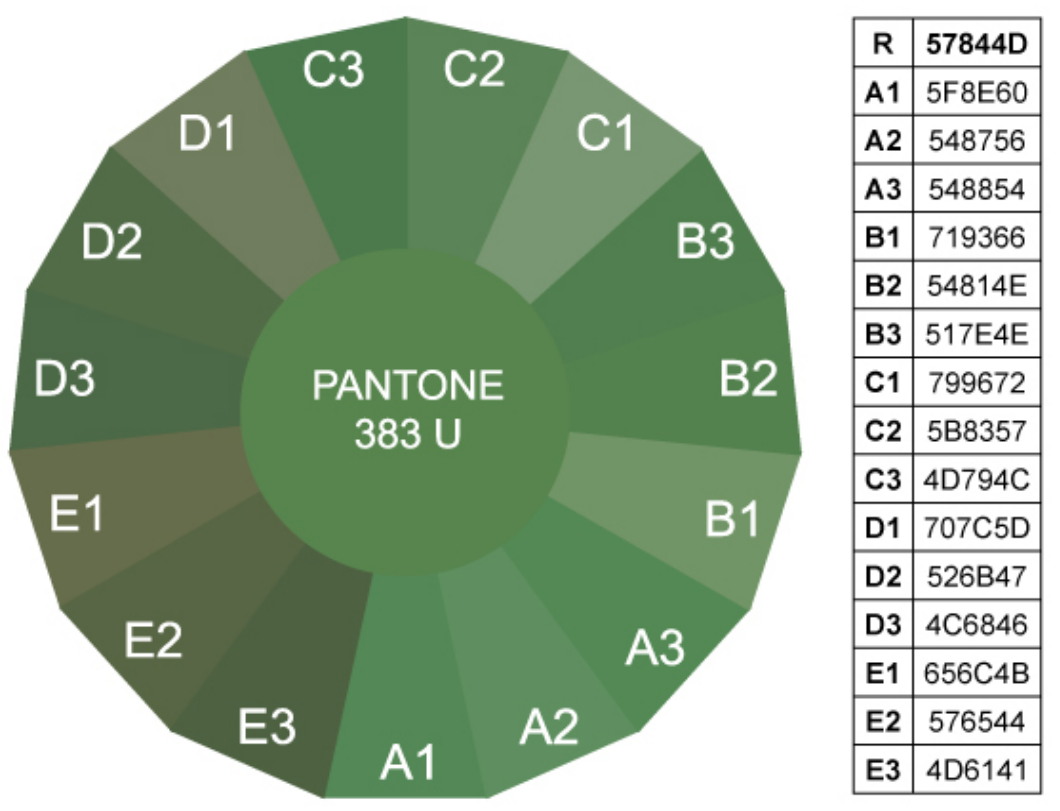

Figure 9: $L A B$ values of each paper displayed in the HEX colour system 


\subsection{Consumer experience testing process}

The survey aimed to find out target consumers' attitudes towards the eco-friendliness of several tea packaging attributes. The survey was conducted on 31 participants, 21 females, 9 males. Most of the respondents were between 21 and 26 years old, and the oldest respondent was 49. As far as education is concerned, they are evenly distributed: 11 respondents have secondary education, 10 higher education, and 10 university education. The participants were chosen from the group of people who care about the environment, who recycle or separate waste, at the same time they were people who consume and buy tea in bulk. Each of the participants was given the packaging without a print. The packaging was made on $140 \mathrm{~g} / \mathrm{m}^{2}$ Flora Tabacco paper so that the design would not influence the further decision of the respondents (CordenonS, 2020). Based on the packaging, participants were questioned about their experience. They were given 15 substrate samples (Figure 8) based on which they filled out a questionnaire to determine, in their own opinion, whether each of them was recycled paper. Only after that were the subjects shown the packaging with the imprint (Figure 8).

The packaging with the print was made on gray $135 \mathrm{~g} / \mathrm{m}^{2}$ paper with a black print not to influence the decisions of the respondents. Based on these samples, the participants had to fill in five points Likert scale questionnaire to decide which one was most aesthetically appealing to them, which was the most suitable for packaging and purchasing, and finally which one seemed to them to be the most ecofriendly. At the end of the evaluation, respondents were interviewed again to explain their decisions.

\section{RESULTS}

Paper $\mathrm{C}$ was rated as the most eco-friendly of the five offered, followed by paper $\mathrm{E}$, then $\mathrm{B}$. The paper $\mathrm{A}$ was not chosen as the environmentally friendly because of its pure white colour. Pressure samples of 50 $\mathrm{N}$ were perceived as the most readable on lighter papers (A1, B1, and C1). Pressure samples of $150 \mathrm{~N}$ were perceived as the most readable on darker papers (D2 and E2). The ratings of $50 \mathrm{~N}$ pressure samples were perceived as eco-friendly for the imprint. The imprints of $400 \mathrm{~N}$ were the lowest rated in terms of ecology, aesthetics, and purchase. Sample C2 was rated as the most environmentally friendly, suitable for purchase and packaging, and aesthetically most acceptable, followed by samples D. Paper A received the worst overall rating, was not suitable for purchase nor is it environmentally friendly (Figure 10).

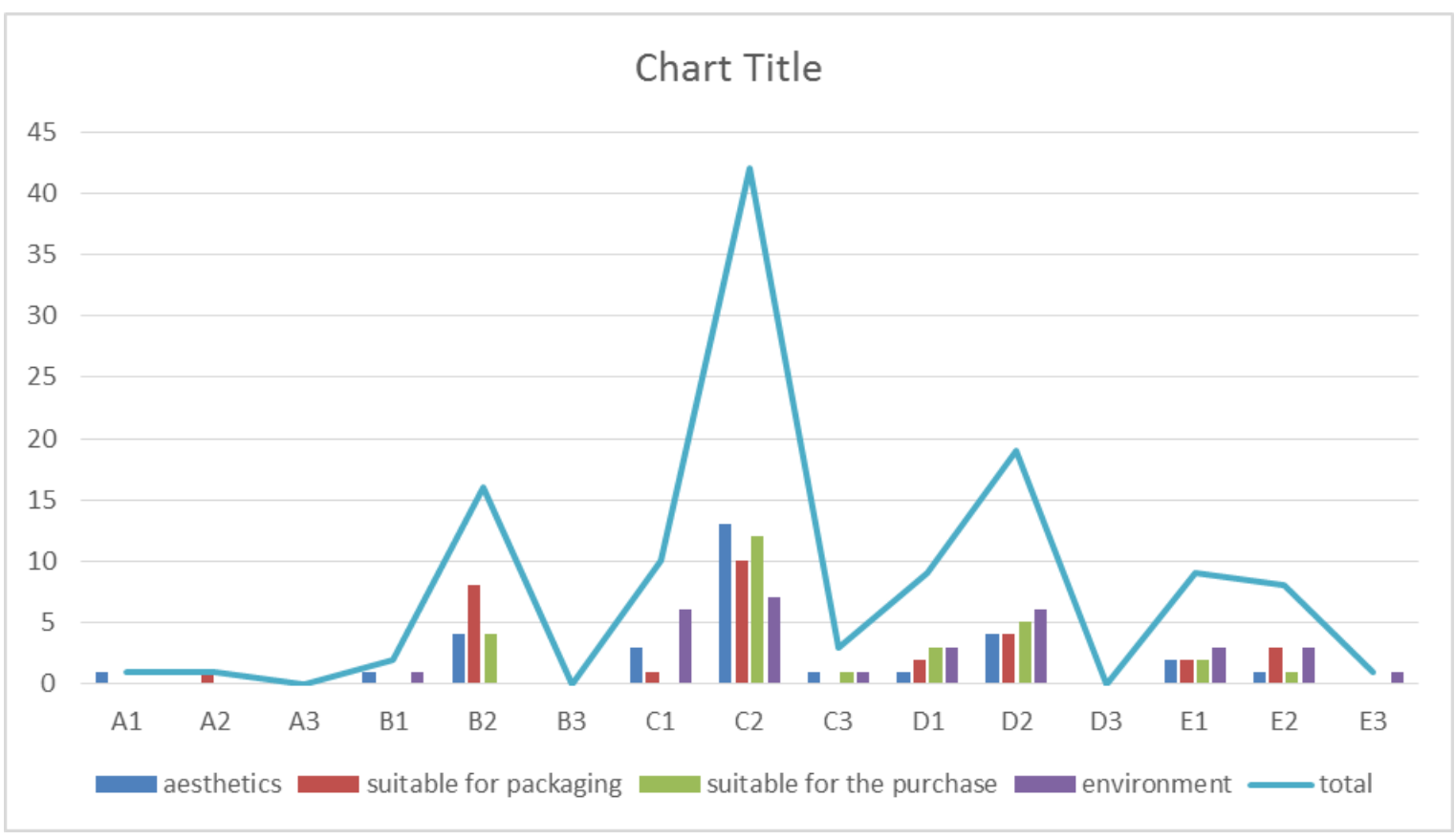

Figure 10: Subjective evaluation results 
All respondents said they would buy packaging. Some explanations were:

"The packaging is a compact, attractive, and a good size to use."

"It's great that the packaging expands after opening. That's how I get tea without any problems. "

"It is practical and opens well. It's nicely lined on the inside. It seems easy to use and provides longlasting storage."

"I would buy it to avoid creating waste because it is biodegradable and recyclable and because it is simple and closes functionally."

"The packaging is more compact and more beautiful than the others that exist on the market. It's great that there are no extra parts to close. "

"I like what can be opened and closed again indefinitely, which makes it practical and I like the look."

Some explanations for the preference of $\mathrm{C} 2$ sample were:

"Somehow this middle one seems to be the most appropriate, the most attractive and the most recycled ..."

"It looks the most natural and the least harmful to the environment."

"I like the colour and the pattern of the paper. The text is visible, and it is in good combination with the paper. It also looks appealing to me as a tea container. "

"It's not an offensive shade, it's a gentle tone. It looks natural and recycled. The green tone of the print can be seen beautifully and in contrast."

"This pattern is the most readable, has a good contrast of text and background, looks the most environmentally friendly, and is very attractive to buy."

"I like the colour and quality of the paper. The print is nicely printed and easy to read."

\section{DISCUSSION}

The user-centered design process enabled the consumers to test and choose the most usable and appropriate packaging form, paper, and printing pressure for eco-friendly tea packaging. Of the five papers with eco-certificates offered, the respondents chose medium paper by brightness and lightest by weight (paper C) as the most environmentally friendly. White paper of higher weight (paper A) was not perceived as environmentally friendly nor suitable for packaging or purchase. Dark recycled papers, made from paper paste, were not acceptable for consumers unless they are coated, but then they lose on environmental friendliness. On smoother papers, the print is perceived as better even at lower printing pressure, while on rougher papers the print is worse regardless of the pressure. The results of LAB colour measurements have been compared with the original UV ink values to analyze the choices of printing pressure and substrate objectively.

\section{CONCLUSIONS}

The consumers' perception of cardboard tea packaging as eco-friendly is influenced by several attributes. The packaging form, closing and binding solution, paper structure, weight, colour, and the width of the lines in the print all play a significant role in the assessment of environmental acceptability. User-centered design and development were proven as a successful framework of processes in which usability goals and the environmental concerns were given extensive attention at each stage of the process. The consumers' choices have shown that the best papers are those in neutral colours with visible fibers as the indication that they are made with a share of recycled paper.

\section{REFERENCES}

[1] Better Meets Reality: "How Many Times Can You Recycle Different Materials? (Plastic, Paper, Metal, Glass, etc.)“, URL: https://www.bettermeetsreality.com/how-many-times-can-you-recycle-differentmaterials-plastic-paper-metal-glass-etc/ (last request: 2020-28-05).

[2] Biosphere Plastic: "Is PLA Compostable?", URL: http://www.biosphereplastic.com/biodegradableplastic/uncategorized/is-pla-compostable/ (last request: 2020-28-05). 
[3] Bond Tech Industries, Eco-Friendly Adhesives: "What makes and eco-friendly adhesive?", URL: https://www.bond-tech-industries.com/about-us/blog/eco-friendly-adhesives/ (last request: 202028-05).

[4] Gasket: "EPDM - tablica karakteristika materijala", URL: http://gasket.hr/documents/EPDM_tablica.pdf (last request: 2020-28-05).

[5] Cordenons: "Flora ecofriendly", URL: http://www.gruppocordenons.com/en/products/schedaprodotto.html?id=2496\&brand_id=38 (last request: $2020-28-05$ ).

[6] Cosper, A.: "Food Packaging - Suitable Materials for presenting tea, coffee, and spices", URL: https://www.desjardin.fr/en/blog/food-packaging-suitable-materials-for-presenting-tea-coffee-andspices\#: :text=Cardboard\%2C\%20like\%20glass\%2C\%20tinplate\%20and,moisture\%20and\%20exposu re\%20to\%20oxygen (last request: 2020-28-05).

[7] Forest Stewardship Council: "About us", URL: https://www.fsc.org/en/page/about-us (last request: 2020-28-05).

[8] [8] Mohawk: "Mohawk's Environmental Program Attributes", URL: https://www.mohawkconnects.com/education/resources/environment (last request: 2020-28-05).

[9] Felix Schoeller Group: "Protection of resources", URL: https://www.felixschoeller.com/en_en/company/sustainability/environment/protection-of-resources.html (last request: 2020-28-05).

[10] Hannah, R., Roser, M.: "Plastic Pollution", Our World in Data, URL: https://ourworldindata.org/plastic-pollution (last request: 2020-28-05).

[11] Sherin, A.: „SustainAble: a handbook of materials and applications for graphic designers and their clients", (Rockport Publishers, Inc., Beverly, Massachusetts, 2008).

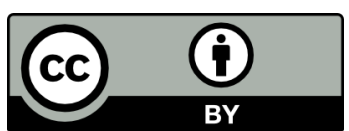

(C) 2020 Authors. Published by the University of Novi Sad, Faculty of Technical Sciences, Department of Graphic Engineering and Design. This article is an open access article distributed under the terms and conditions of the Creative Commons Attribution license 3.0 Serbia (http://creativecommons.org/licenses/by/3.0/rs/). 